\title{
Electronic Slideshow Presentations in the Higher Education Teaching and Learning Process
}

\author{
Carlos Miguel Ferreira ${ }^{1}$, Ana Isabel Santos ${ }^{2}$, Sandro Serpa ${ }^{3}$ \\ ${ }^{1}$ Interdisciplinary Centre of Social Sciences-CICS.NOVA, Polytechnic Institute of Castelo Branco, Estoril Higher \\ Institute for Tourism and Hotel Studies, 1069-061 Lisbon, Portugal \\ ${ }^{2}$ University of the Azores, Faculty of Social and Human Sciences, Department of Education; Interdisciplinary Centre for \\ Childhood and Adolescence-NICA -UAc, Azores, Portugal \\ ${ }^{3}$ Department of Sociology, Faculty of Social and Human Sciences, University of the Azores; Interdisciplinary Centre of \\ Social Sciences - CICS.UAc/CICS.NOVA.UAc, and Interdisciplinary Centre for Childhood and Adolescence - NICA \\ - UAc, Azores, Portugal
}

Correspondence: Carlos Miguel Ferreira, Interdisciplinary Centre of Social Sciences-CICS.NOVA, Polytechnic Institute of Castelo Branco, Estoril Higher Institute for Tourism and Hotel Studies, 1069-061 Lisbon, Portugal.

Received: November 26, 2017

Accepted: January 26, $2018 \quad$ Online Published: January 27, 2018

doi:10.11114/jets.v6i2.2818

URL: https://doi.org/10.11114/jets.v6i2.2818

\begin{abstract}
The use of electronic slide presentations (ESP), usually through PowerPoint or Prezi software, has become widespread in higher education and is part of the expectations and perceptions of both teachers and students of how a successful and quality class should be. Is this dissemination of ESP use justified by the pedagogical quality fostered in learning? While its use can help focus attention on the content of the subject during classes, there are also limitations in this process, both in the dimension of teaching, by the teacher, and in the dimension of learning, by the student. This paper seeks to provide a contribution to the debate on this topic, and the advantages and limitations in using ESP. It is concluded that there is a need, on the one hand, to define the use of ESP, by assaying their application, as well as, on the other hand, to simultaneously develop other pedagogical ways of teaching, whose articulation can make the student's role more active and pertinent, and enable the feedback to the student on the part of the teacher, so that it may be possible to regulate the teaching and learning process in a timely manner.
\end{abstract}

Keywords: electronic slideshow presentations, PowerPoint, Prezi, higher education, teaching, learning

\section{Introduction}

The model of teaching through lectures, centred on the teacher, still plays a central role and dictates the mainstream pedagogical strategy of higher education teaching (Pros \& Tarrida, 2017; Garrett, 2016; Akbar, 2016; Moulton, Türkay \& Kosslyn, 2017). In the context of application of this teaching model, there is currently some generalisation of the use of electronic slideshow presentations (ESP) in higher education classes, especially in the form of a PowerPoint slideshow or, more recently, in Prezi (Inoue-Smith, 2016; Naik, 2017; Chou, Chang, \& Lu, 2015; Babbs \& Ross, 2009; Tejada-Llacsa \& Cahuana-Aparco, 2016; Worthington \& Levasseur, 2015; Schoeman, 2013; Hill, Arford, Lubitow, \& Smollin, 2012; Kosslyn, Kievit, Russell, \& Shephard, 2012; Garrett, 2016), although there is no unanimity regarding the merits of this software (Inoue-Smith, 2016; Pros \& Tarrida, 2017; Moulton et al., 2017). This article addresses presentations in both PowerPoint and Prezi, given that there seem to be no clear and undeniable advantages in terms of learning using one or the other program (Chou et al., 2015; Moulton et al., 2017), although there is a clear dominance of PowerPoint use (Garrett, 2016).

This pedagogical practice of "traditional powerpoint dominated lecturing" (Wharton, Goodwin, \& Cameron, 2014, p. 72) seems to meet, in general, the expectations of many teachers and students (Savoy, Proctor, \& Salvendy, 2009; Hill et al., 2012; Inoue-Smith, 2016; Kosslyn et al., 2012), which justifies, to a large extent, its use in what has been called by Hill et al. (2012) "PowerPoint culture": "The software's ubiquity, popularity with students, and instructors' perceptions of student expectations speak to a growing PowerPoint culture in the university - It has become a normative feature of academic instruction" (p. 253). 
However, this spreading of ESP in the academy seems to take place, generally, in a rather uncritical way: "Unfortunately, its ever-expanding influence in the classroom has failed to produce a comparable expansion in learning outcomes" (Worthington, \& Levasseur, 2015, p. 14); or also, "Few professors truly use PowerPoint well. The ubiquity of PowerPoint in the classroom means that it must be further evaluated" (Inoue-Smith, 2015, p. 10).

These stances are reinforced by Pros and Tarrida (2017), who consider that lecture slides are a very abundant product in the teaching practice in general and in the higher education practice in particular, although this does not necessarily entail any instructional advantage.

Why does this happen? Cadena and Coutinho (2017) point out some central factors of this ESP expansion in higher education: its cost is low; its production is straightforward; it is a practical resource; it is easy to use and can be used at different moments; it is more attractive for its multimedia potential; it enables control of classroom activities according to the presentation sequence; it is easily shared (in whole or in parts selected by the teacher) with students; and it may help in the structuring and sequencing of the presentation itself.

However, are there pedagogical reasons that justify such a widespread use of ESPs? By reflecting on a topic that still needs more in-depth studies in the understanding of its implications (Naik, 2017; Babbs \& Ross, 2009; Hill et al., 2012; Cadena \& Coutinho, 2017), this article seeks to contribute to a greater clarification of the questions regarding the advantages and limitations of the pedagogical use of ESP as a teaching and learning strategy in higher education in promoting a successful teaching and learning process.

\section{Electronic Slideshow Presentations as a Pedagogical Strategy}

At a time when "the lecture class as a format for higher education is under attack more than ever" (Alpert, 2016, p. 1) is acknowledged, ESP may contribute to change in a positive way - to a certain extent and if well used - the way how both teachers and students perceive a class should consist of.

Regarding teachers,

"They indicated that with the PowerPoint slides they started to think differently about their lessons, revealed the new content more easily and systematically, taught the subject content in a much more effective way, and that comparisons and contrast became easier, and complex events were easier to explain" (Schoeman, 2013 p. 81).

As for students, "The literature review demonstrates that PowerPoint can help to focus students' attention in the classroom, and can make it easier for students to follow the lecture" (Inoue-Smith, 2015, p. 12).

However, the use of ESP in a learning context is a complex pedagogical strategy and not necessarily a positive one. Several studies point to possible disadvantages, at various levels, of the use of ESP (in particular Schoeman, 2013; Hill et al., 2012; Naik, 2017; Inoue-Smith, 2016; Pros \& Tarrida, 2017; Kosslyn et al., 2012; Inoue-Smith, 2015), summarised below:

- excessive reading of the slides;

- over-simplification of the contents;

- higher importance ascribed to short-term memorisation rather than the understanding of contents;

- excessive dependence on technological conditions (if something cannot be slide-shown it can be very difficult to continue with the teaching process);

- little interaction with students;

- limited discussion with students on the subjects addressed;

- passivity on the part of students;

- dependence on slides on the part of students;

- an uncritical perspective of the students, who take notes without understanding the subject;

- if it is the only pedagogical strategy, classes can be boring.

From all the above in a counterproductive way, the following may happen:

"The PowerPoint slide presentation, regardless of the kind of knowledge it is serving to frame, exercises a powerful sway over the teacher in the moments of teaching, at times appearing as an impenetrable obstacle rather than a generative support to the teacher desiring to pursue her pedagogical sense of tact" (Adams, 2010, p. 10).

The literature on this topic demonstrates that the provision of slides to students may not be, per se, a solution to this obstacle, because, even with access to slides, students may have difficulties in understanding and developing, in a reasoned way, the necessarily simplified information that they entail, which may have, as demonstrated in the research 
by Worthington and Levasseur (2015), a negative impact on students' academic performance, probably because it encourages passivity in student learning.

Regarding this provision of slides to students, before or after their presentation in class, and students' learning, Babbs and Ross (2009) conclude, in a very interesting and perhaps paradoxical way in relation to some existent perceptions, that

"Students were more likely to use slides as a substitute for attending lecture if they received lecture slides after class.

If lecture slides are made available before class, students bear the responsibility for knowing how to use slides for notetaking so that they work best for their own learning style. This also includes understanding that not all lecture material will be contained on the online lecture slides, and therefore they should not be using them as a substitute for attending class. Most importantly, it is essential that students realize that having access to the professor's lecture slides before lecture does not always lead to better exam performance. Rather, slides are simply another tool that must be incorporated into effective study strategies" (pp. 878-879).

The way to fight some of the limitations that the use of ESP may entail is to begin by recognising that teachers' and students' preference and expectations do not always have a direct relationship with performance in terms of learning (Savoy et al., 2009; Cadena \& Coutinho, 2017), acknowledging the difference between memorisation-based teaching and comprehension-centred teaching (Pros \& Tarrida, 2017).

In fact, the teaching and learning process always takes place in a specific context and preferably with intentionality on the part of the teacher (Naik, 2017; Adam, 2010; Harris, 2011), but bearing in mind the need to seek, in many and distinct moments, to foster an active lecturing, through teacher-student(s) interaction during the slideshow (Inoue-Smith, 2016; Pros \& Tarrida, 2017).

On the other hand, the use of ESP itself is not uniform and seems to differ according to the scientific area in question. For example, Garrett (2016) shows this difference in his analysis of PowerPoint files created by an academic publisher to supplement textbooks, and from his conclusions we highlight that hard-scientific disciplines use less complex writing and more words than soft scientific disciplines:

"While students generally prefer slides with high-quality graphics, faculty in hard disciplines should carefully consider whether simpler images might be more appropriate. While short bullet points are generally seen as superior, faculty in soft disciplines may need more words on each slide, simply due to their disciplinary approach to knowledge. Best practices are useful as rough heuristics, but wisdom is needed in determining how general rules apply to individual classrooms" (p. 377).

However, even assuming that the rules of a technical nature - that guide the development of potentially learning-enhancing slides - are fulfilled, as is the necessary and sufficient time devoted to the slide and to the amount of information provided (Flores-Hernández \& Villamar-Chulín, 2012; Inoue-Smith, 2016; Kosslyn et al., 2012; Garrett, 2016; Cadena \& Coutinho, 2017), its successful application in the classroom context is not automatic or simplistic, and factors such as the purpose of the class and the type and amount of information involved should be considered (Tejada-Llacsa \& Cahuana-Aparco, 2016; Inoue-Smith, 2015; Garrett, 2016).

In sum, we point out as general principles that the information provided in ESP should be contained and controlled to be properly apprehended; the presenter's need for intentionality in delimiting the form and content of ESP for each specific context; and, finally, as referred by Kosslyn et al. (2012), the need to facilitate the work of the audience in the desired learning.

\section{Discussion}

From the previous discussion, it should be emphasised that ESP, if adequately used, allow certain contents to be more accessible by maximising learning and, thus, academic results. However, a great challenge emerges in relation to ESP: how are they used? As Inoue-Smith (2015) points out,

"Undeniably, PowerPoint has merit, but now is the time to think carefully about its use: especially, how and when to use it in classroom-based lectures. The most important question is that how can professors complement PowerPoint to ensure effective teaching in the classroom?" (p. 17).

To conclude, teachers should take into account that, by using ESP, they are implementing a specific form of teaching and learning, about which they should take conscious and intentional options at various levels (Adams, 2010), seeking to reflect on the advantages and disadvantages of their use in each specific situation. This is because, in short, technology is not necessarily synonymous with better learning (Schoeman, 2013; Chou et al., 2015; Savoy et al., 2009), and thus it is necessary to regard it as a possible pedagogical strategy, among many others, articulating it according to 
the scientific discipline in question, its features, the students, and the whole surrounding context (Babb \& Ross, 2009; Hill et al., 2012; Naik, 2017; Cadena \& Coutinho, 2017; Garrett, 2016).

Regarding students, their way of looking at and using ESP should also be carefully thought out and discussed, so that the teaching and learning process is not reduced to the sheer reading of items used in some technological device, but that, rather, it may be understood as a tool that leads to research and to the deepening of knowledge.

\section{Acknowledgements}

Acknowledgments: University of the Azores, Interdisciplinary Centre of Social Sciences CICS.UAc/CICS.NOVA.UAc, UID/SOC/04647/2013, with the financial support of FCT/MEC through national funds and, when applicable, co-financed by FEDER under the PT2020 Partnership Agreement.

The authors acknowledge the comments and suggestion by three anonymous reviewers.

\section{References}

Adams, C. A. (2010). Teachers building dwelling thinking with slideware. Indo-Pacific Journal of Phenomenology, 10(1), 1-12. https://doi.org/10.2989/ipjp.2010.10.1.3.1075

Akbar, M. (2016). Digital technology shaping teaching practices in higher education. Front. ICT, 3(1), 1-5. https://doi.org/10.3389/fict.2016.00001

Alpert, F. (2016). Revitalizing the live lecture class with instructor-created videos. SAGE Open, 6(4), 1-12. https://doi.org/10.1177/2158244016680686

Babb, K. A., \& Ross, C. (2009). The timing of online lecture slide availability and its effect on attendance, participation, and exam performance. Computers \& Education, 52(4), 868-881. https://doi.org/10.1016/j.compedu.2008.12.009

Cadena, R. A., \& Coutinho, S. G. (2017). Dez pontos sobre apresentações de slides, suas características e implicações para a prática docente. [Ten points about slideshow presentations, their characteristics, and implications for teaching practice]. Revista Principia - Divulgação Científica e Tecnológica do IFPB, 1(33), 58-66. https://doi.org/10.18265/1517-03062015v1n33p58-66

Chou, P. N., Chang, C. C., \& Lu, P. F. (2015). Prezi versus PowerPoint: The effects of varied digital presentation tools on students' learning performance. Computers \& Education, 91, 73-82. https://doi.org/10.1016/j.compedu.2015.10.020

Flores-Hernández, F., \& Villamar-Chulín, J. (2012). Elementos para el desarrollo de presentaciones académicas en PowerPoint. [Elements for the development of academic presentations in PowerPoint]. Inv Ed Med., 1(3), 152-156

Garrett, N. (2016). How do academic disciplines use PowerPoint? Innov High Educ, 41(5), 365-380. https://doi.org/10.1007/s10755-016-9381-8

Harris, D. (2011). Presentation software: Pedagogical constraints and potentials. Journal of Hospitality, Leisure, Sport and Tourism Education, 10(1), 72-84. https://doi.org/10.3794/johlste.101.339

Hill, A., Arford, T., Lubitow, A., \& Smollin, L. M. (2012). "I'm ambivalent about it": The dilemmas of PowerPoint. Teaching Sociology, 40(3), 242-256. https://doi.org/10.1177/0092055x12444071

Inoue-Smith, Y. (2015). Using PowerPoint effectively for classroom based lectures. The Journal of the World Universities Forum, 8(2), 9-19.

Inoue-Smith, Y. (2016). College-based case studies in using PowerPoint effectively. Cogent Education, 3(1), 1-15, 1127745. https://doi.org/10.1080/2331186x.2015.1127745

Kosslyn, S. M., Kievit, R. A., Russell, A. G., \& Shephard, J. M. (2012). PowerPoint ${ }^{\circledR}$ presentation flaws and failures: a psychological analysis. Front. Psychology, 3(230), 1-22. https://doi.org/10.3389/fpsyg.2012.00230

Moulton, S. T., Türkay, S., \& Kosslyn, S. M. (2017). Does a presentation's medium affect its message? PowerPoint, Prezi, and oral presentations. PLoS ONE, 12(7), 1-39. https://doi.org/10.1371/journal.pone.0178774

Naik, N. (2017). Dual PowerPoint presentation approach for students with special educational needs and note-takers. European Journal of Special Needs Education, 32(1), 146-152. http://dx.doi.org/10.1080/08856257.2016.1254970

Pros, R. C., \& Tarrida, A. C. (2017). Percepción del aprendizaje, procedimientos de evaluación y uso de la tecnología PowerPoint en la formación universitaria de Medicina. [Perception of learning, assessment procedures and the use of PowerPoint technology in University Studies of Medicine]. Intangible Capital, 13(2), 302-318. http://dx.doi.org/10.3926/ic.814

Savoy, A., Proctor, R. W., \& Salvendy, G. (2009). Information retention from PowerPoint and traditional lectures. 
Computers \& Education, 52(4), 858-867. http://dx.doi.org/10.1016/j.compedu.2008.12.005

Schoeman, S. (2013). Presentation technology as a mediator of learners' retention and comprehension in a History classroom. Yesterday \& Today, 9, 67-90.

Tejada-Llacsa, P. J., \& Cahuana-Aparco, J. (2016). Uso de PowerPoint en clases: ¿es necesario estudiarlo? [Using PowerPoint in class: Is it necessary to study it?]. Rev Med Chile, 144(5), 682-683 (Cartas al Editor / Letters to the Editor). http://dx.doi.org/10.4067/S0034-98872016000500021

Wharton, C. Y, Goodwin, L. J., \& Cameron, A. J. (2014). Living up to our students' expectations - using student voice to influence the way academics think about their undergraduates learning and their own teaching. International Journal of Higher Education, 3(4), 72-84. https://doi.org/10.5430/ijhe.v3n4p72

Worthington, D. L., \& Levasseur, D. G. (2015). To provide or not to provide course PowerPoint ${ }^{\circledR}$ slides? The impact of instructor-provided slides upon student attendance and performance. Computers \& Education, 85, 14-22. https://doi.org/10.1016/j.compedu.2015.02.002

\section{Copyrights}

Copyright for this article is retained by the author(s), with first publication rights granted to the journal.

This is an open-access article distributed under the terms and conditions of the Creative Commons Attribution license which permits unrestricted use, distribution, and reproduction in any medium, provided the original work is properly cited. 